\title{
COLANDO FRAGMENTOS DO MUNDO DA VIDA SOCIAL: RECORTES DO COTIDIANO DE CAMPONESES DO BAIXO TOCANTINS PARAENSE
}

\author{
Vitória Mendes Alves ${ }^{1}$ \\ Israel Martins Araujo ${ }^{2}$
}

Este ensaio visual é parte de uma pesquisa de dissertação da autora (Alves, 2020) a respeito do mundo da vida cotidiana (Schutz, 1970) de camponeses agroextrativistas no Pará, especificamente no baixo Tocantins, região das ilhas do município de Mocajuba. Tendo como método a etnografia sensorial (Pink, 2009), a pesquisa interdisciplinar discute a relação entre corpo, ambiente e formas de aprendizagem técnica com a virtuosidade dos indicadores socioambientais (Costa, Fernandes, 2016) e argumenta que tais técnicas não são transmitidas, mas ensinadas e aprendidas por meio de um complexo engajamento sensorial com o ambiente (Lave, 2015) e o entrelaçamento corpo-ambiente (Ingold, 2015) está no cerne do cotidiano camponês, o que implica em interpretá-lo superando os dualismos cultura/natureza e produção/reprodução. Essas relações explicam, parcialmente, a virtuosidade socioambiental.

Mocajuba é um município que possui uma região de ilhas ordenada territorialmente de duas formas distintas. São quatro Projetos de Assentamentos Agroextrativistas (PAE): Ilha Grande de Conceição de Mocajuba, Ilha Grande de Vizeu, Ilha de Angapijó e Ilha de Tauré. Existe, também, um território quilombola, o Distrito de Porto Grande. Estas porções territoriais são limítrofes aos municípios Cametá e Baião. Na Ilha Grande da Conceição, habitam cerca de 280 famílias em 3 comunidades: São Joaquim, Santana e Costa de Santana. Nesta localidade foram reunidos a maior parte dos materiais utilizados no ensaio.

Durante o processo de observar e participar das vidas dos interlocutores, foram recolhidos alguns materiais de forma espontânea e menos sistemática. São pequenos

\footnotetext{
${ }^{1}$ Universidade Federal do Pará, Brasil. E-mail: vimendesalv@gmail.com ORCID id: https://orcid.org/0000-0003-3629-1826

${ }^{2}$ Universidade de Brasília, Brasil. E-mail: israelmacs@gmail.com ORCID id: https://orcid.org/0000-0003-0239-7171
} 
objetos, textos e imagens que, de alguma forma, fazem parte do mundo cotidiano de São Joaquim e contam como estas pessoas vivem: cartelas de bingo, anotações sobre o calendário produtivo de uma família, listas de instrumentos utilizados na construção de barcos, desenhos feitos por crianças e adultos, folhas, trechos de conversas. Tradicionalmente, tais fragmentos deveriam ficar nos anexos de um trabalho acadêmico, no entanto, sempre enxergamos nestas pequenas coisas um grande valor, e por isso apresentamos esses fragmentos não como exemplos explicativos dos dados etnográficos, mas como corpo textual explicativo tão importante quanto os presentes em um formato prosaico.

A etnografia sensorial conforme descrita por Pink (2009) fornece amparo metodológico para pensar em fragmentos como estes como partes tão válidas quanto a narrativa etnográfica. A atenção aos sentidos, que percorre todos os processos, do campo à análise, requer do pesquisador uma atitude autorreflexiva e autoconsciente. Isto é, se o interesse da pesquisa é observar quais as atribuições e usos do corpo no mundo da vida, é preciso que o próprio pesquisador esteja atento às suas experiências sensoriais e modos de aprendizado durante a vivência em campo. Não há, portanto, um protocolo fechado ou série de instruções delimitadas sobre como fazer isso na prática, cabe aos etnógrafos descobrir procedimentos que os auxiliem na procura por respostas à pergunta de pesquisa.

Para a autora, existem diferentes métodos na etnografia sensorial que nos levam ao mundo das pessoas; eles nos conduzem às experiências dos outros através de caminhos diferentes. Por isso a prática da etnografia sensorial permite, também, trabalhar com os dados coproduzidos em campo por meio de outros formatos além do texto escrito, como conteúdos audiovisuais ou até mesmo artísticos.

Aqui, escolhemos trabalhar com estes materiais por meio de colagens. Em parceria entre os autores, escaneamos e fotografamos alguns objetos e colamos digitalmente em camadas por meio do programa de edição de imagem Photoshop, resultando nas seis peças a seguir. Esse processo começa na efetiva reunião dos objetos disponíveis, em seguida com o planejamento de cada uma das peças de acordo com um tema, por meio de desenhos manuais e esquemáticos. O processo seguinte foi escanear os objetos físicos. Em seguida, manipulamos as imagens digitalmente no Photoshop, sobrepondo camadas de objetos escaneados e fotos. Escolhemos como fontes padrão dos textos Josefin Sans e Sifonn, disponíveis gratuitamente na internet.

Uma grande inspiração para a composição das peças a seguir é o trabalho "Weathering: a graphic essay" (Azevedo, Schroer, 2016) onde as autoras colaboraram 
em uma produção gráfica sobre a relação entre falcões, falcoeiros e seu meio, nas vias de uma proposta da categoria desenho enquanto expressão da análise antropológica. Percebemos o trabalho de composição das colagens, enquanto opção metodológica de apresentação de dados etnográficos, tão importante como o desenho na composição de um modelo de análise antropológica tendo em vista alguns pontos: a colagem requer dos pesquisadores sensibilidade na hora de encaixar diferentes materiais, opção por diagramações diversas, fontes e até posição dos elementos na peça a fim de compor um texto que facilite sua explicação e descrição antropológica do campo estudado; requer uma certa latitude, um certo refinamento das percepções de quais elementos, em quais contextos, conseguem narrar com mais fidelidade o cotidiano daquelas pessoas.

No caso do presente ensaio, considerando a reunião de objetos presentes durante o campo, não se pretende com eles fazer uma arqueologia dos sentidos da vida camponesa, como se representassem em definitivo os processos estudados mas sim tentar organizá-los de forma a compor uma explicação visual, uma opção de apresentação de análise antropológica, de determinados temas da vida camponesa como a pesca, o extrativismo, o lazer, a navegação e vida cotidiana e religiosa. 


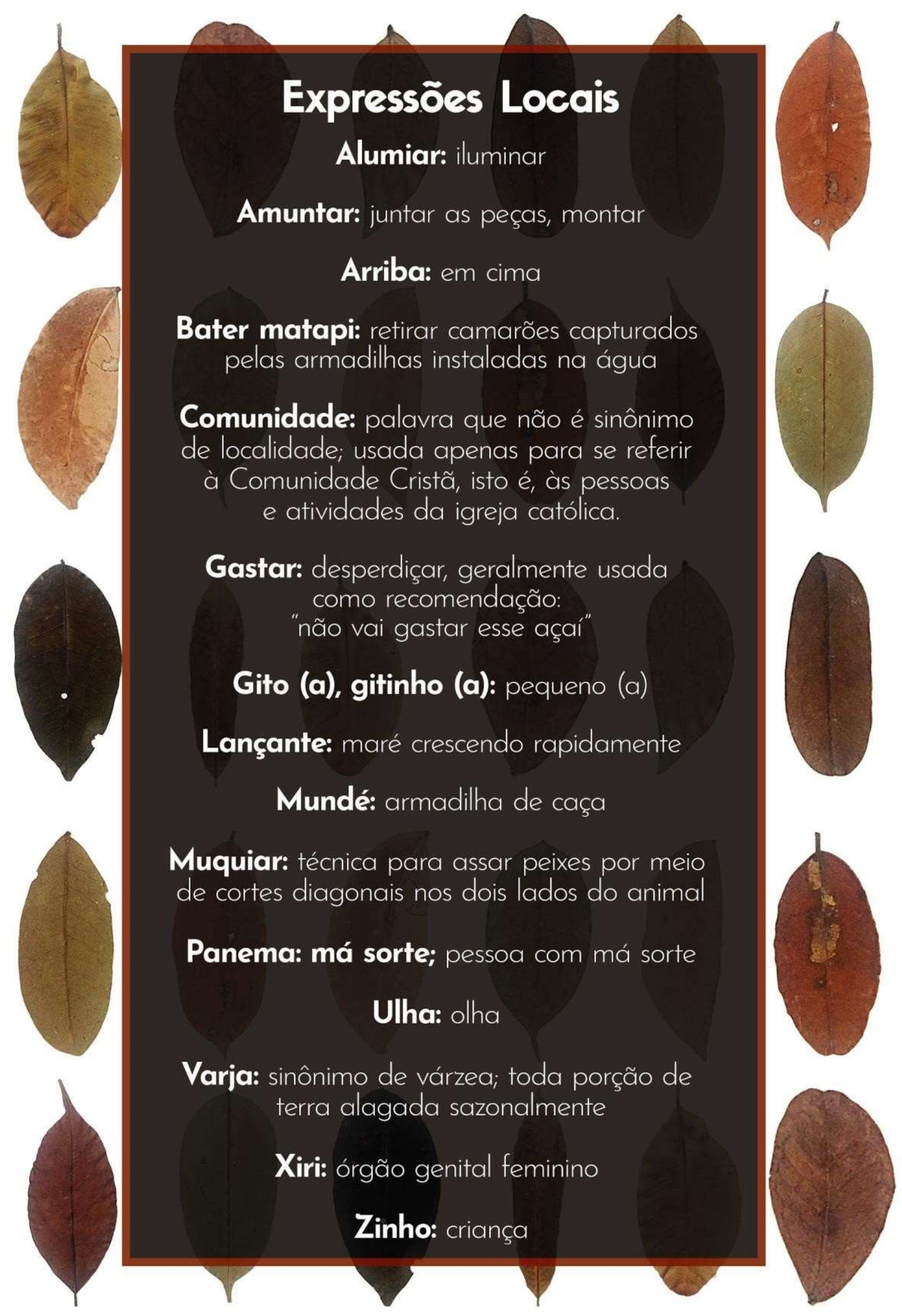


Inventário de animais da regiāo segundo a memória e as classificaçōes (qualidades) de Pagão, pescador de

\section{São Joaquim}

Qualidades: da água, do céu, do mato (caça) e de casa.

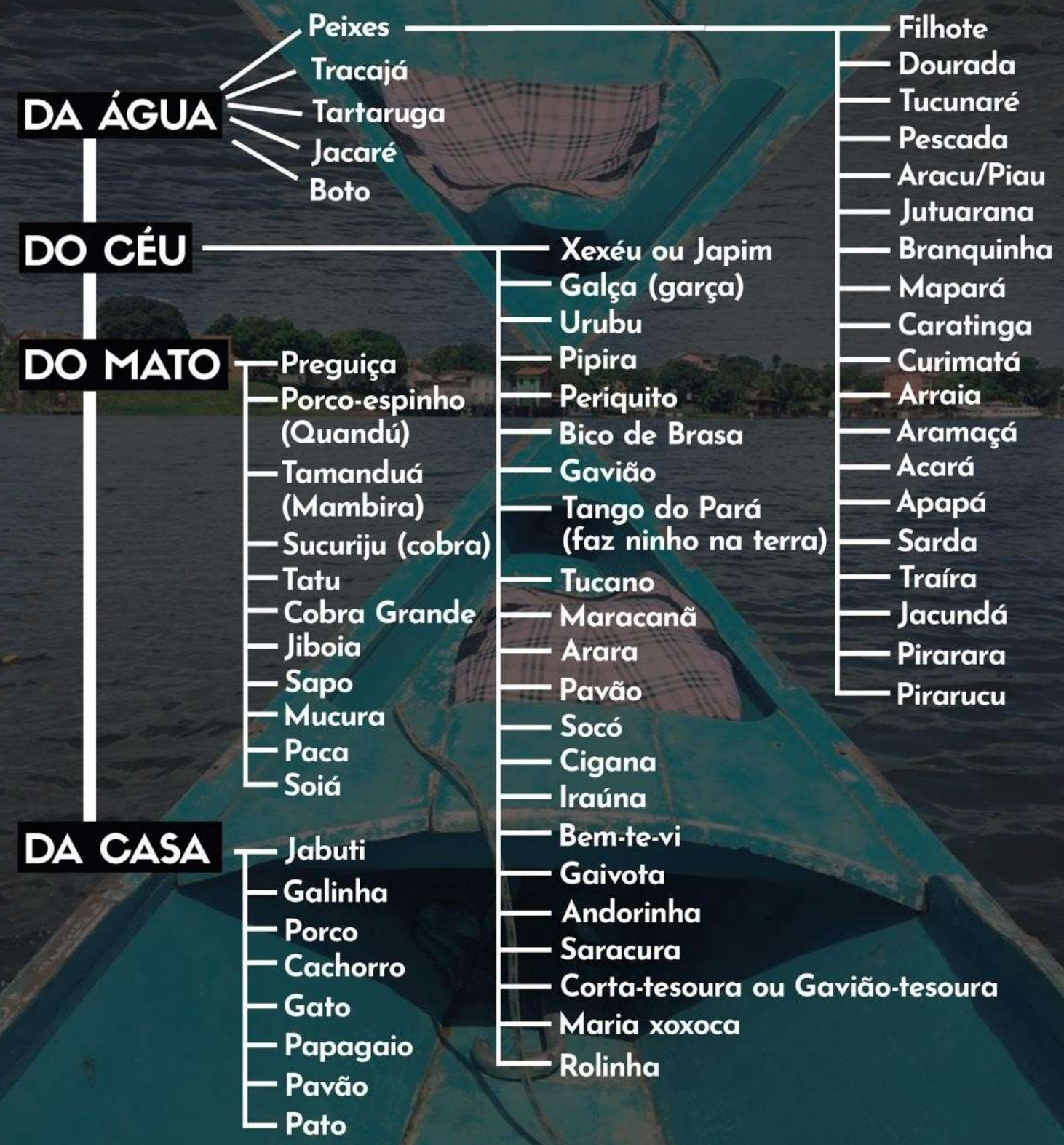




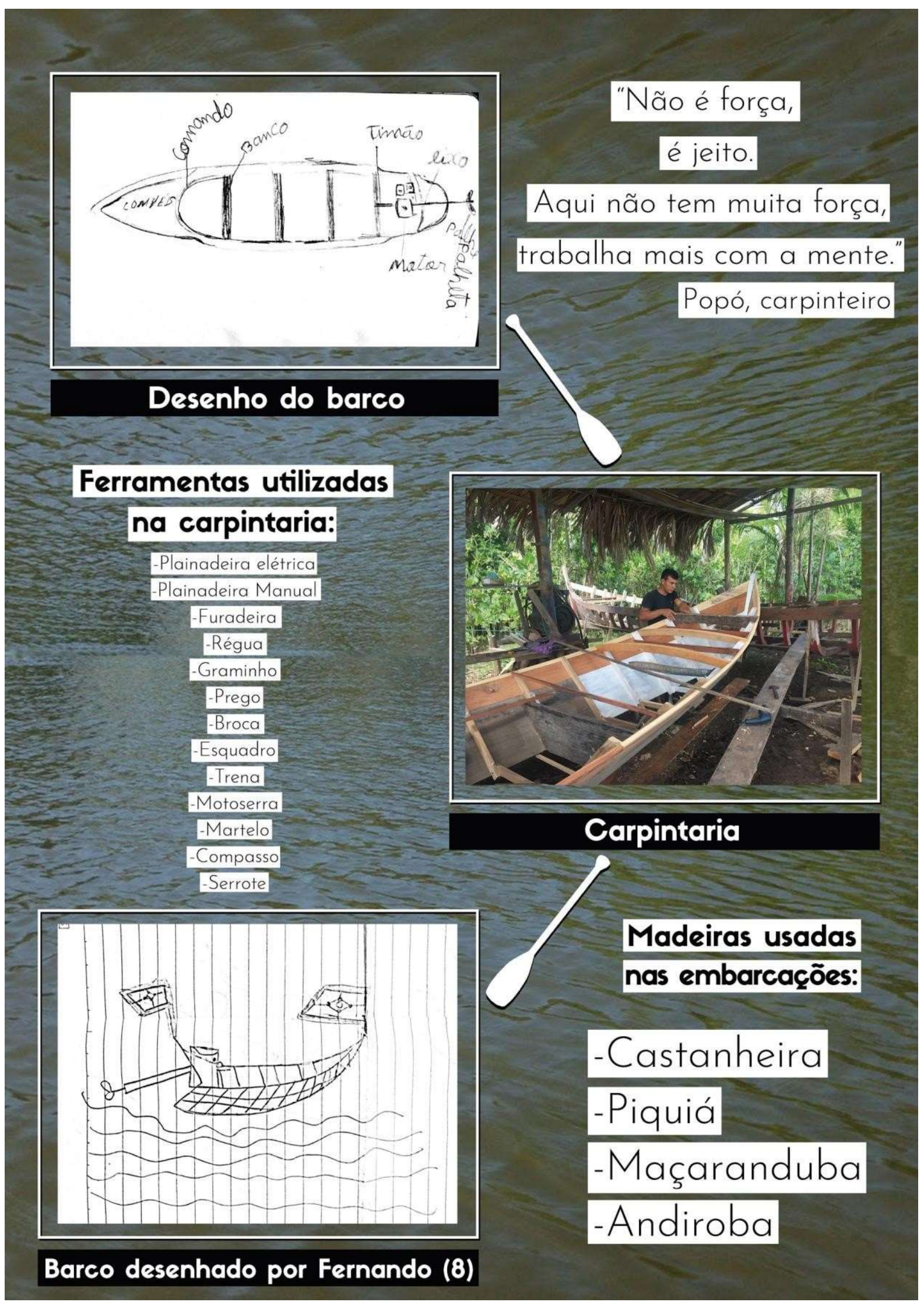




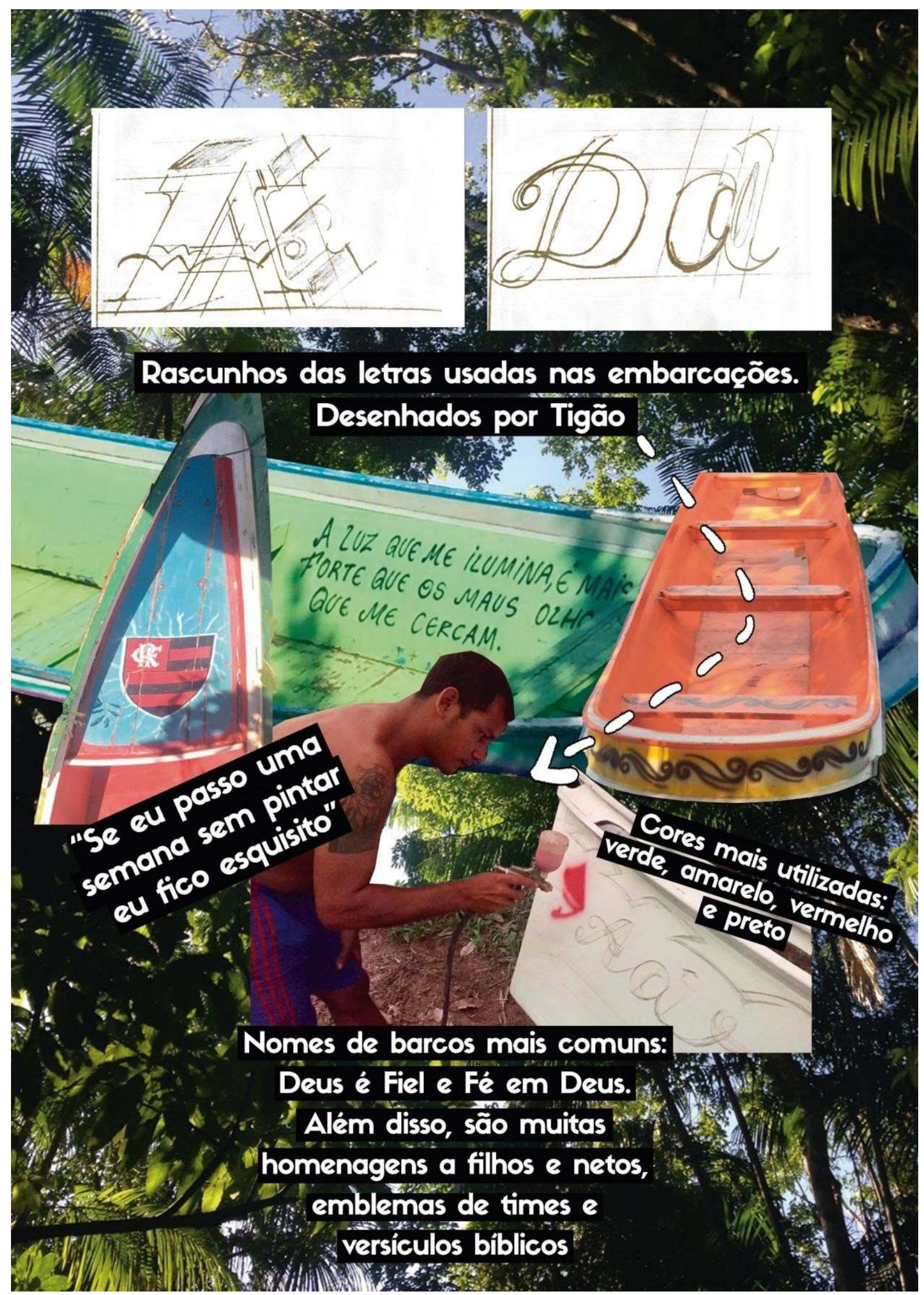




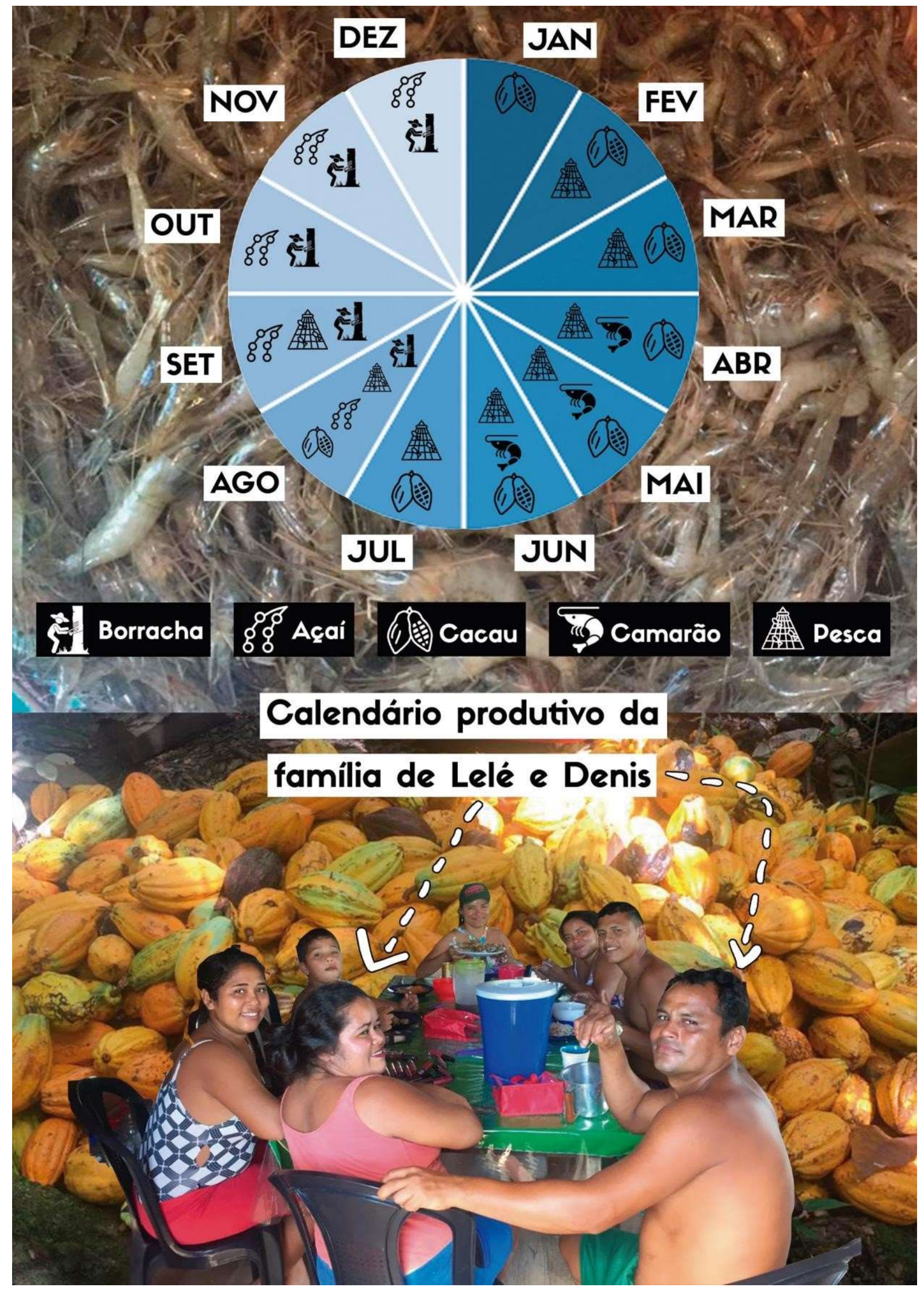




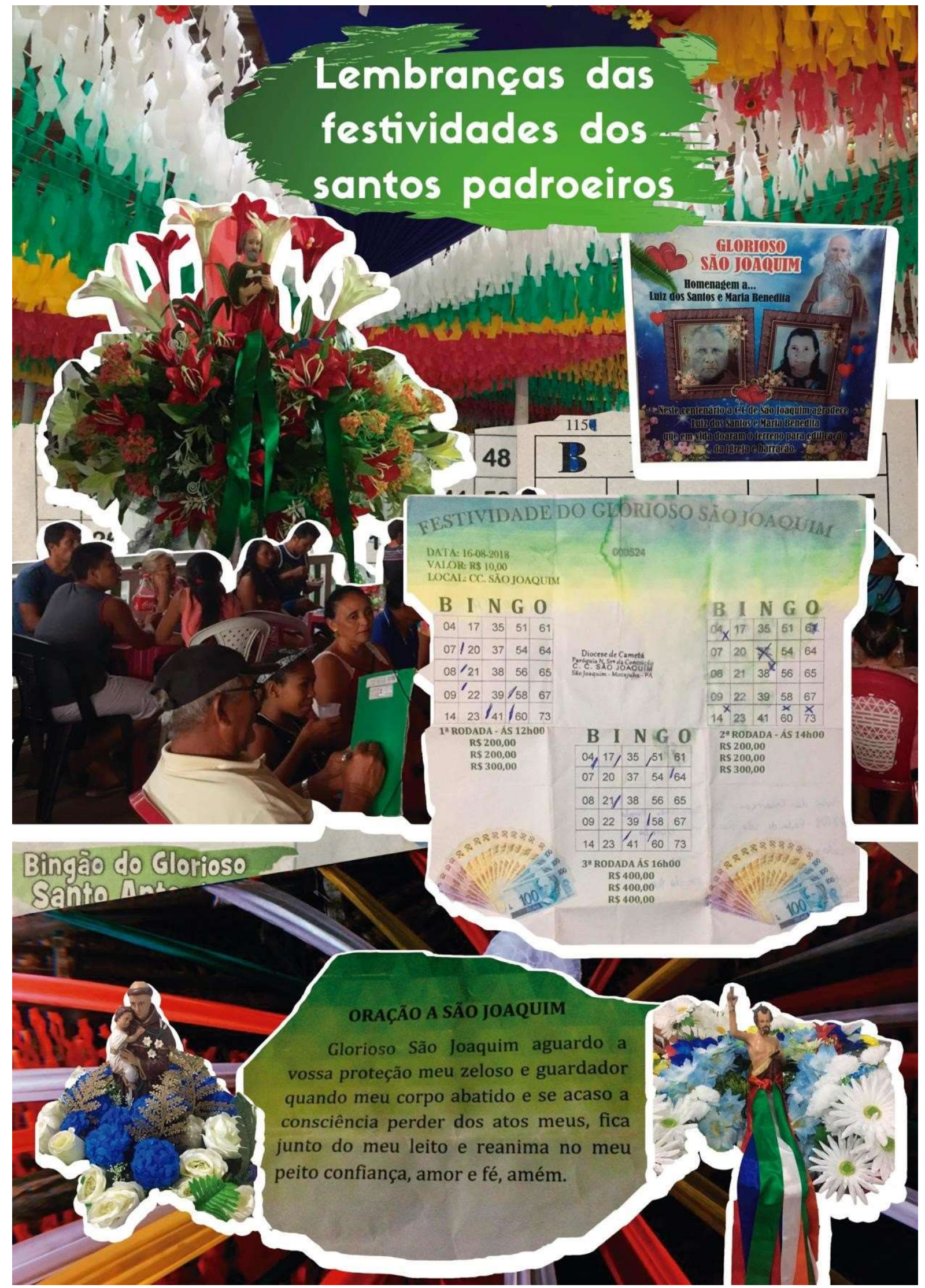




\section{REFERÊNCIAS}

ALVES, Vitória M. CORPO, AMBIENTE E APRENDIZAGEM: Etnografia sensorial sobre o mundo da vida cotidiana em comunidades camponesas amazônicas. 2020. Dissertação (Mestrado em Planejamento do Desenvolvimento)- Programa de Pós-Graduação em Desenvolvimento Sustentável do Trópico Úmido, Núcleo de Altos Estudos Amazônicos, Universidade Federal do Pará, Belém, 2020.

AZEVEDO, Aina; SCHROER, Sara Asu. Weathering: a grafic essay. Vibrant- Virtual Brazilian Anthropology. v 3. n 2. 2016. Disponível em:

http://www.vibrant.org.br/issues/weathering-a-graphic-essay/. Acesso em: 5 jul 2019.

COSTA, Francisco de Assis; FERNANDES, Danilo Araujo. Dinâmica Agrária, Instituições e Governança Territorial para o Desenvolvimento Sustentável da Amazônia. Revista de Economia Contemporânea (Impresso), v. 20, p. 517-552, 2016.

INGOLD, Tim. Estar vivo: ensaios sobre movimento, conhecimento e descrição. Petrópolis, RJ. Vozes: 2015.

LAVE, Jean. Aprendizagem como/na prática. In: Horizontes Antropológicos. Porto Alegre, ano 21, n. 44, jul./dez. 2015.

PINK, Sarah. Doing sensory etnography. Londres. Sarge: 2009.

SCHUTZ, Alfred. Fenomenologia e Relações Sociais: textos escolhidos de Alfred Schutz. Rio de Janeiro. Zahar: 1970.

Recebido: 10/02/2021

Aprovado: 01/04/2021 